\title{
LEITURA DE TEXTO LITERÁRIO SOB A ÓTICA DA PLURIDISCURSIVIDADE BAKHTINIANA: REFLEXÕES SOBRE A PRÁTICA DE ENSINO EM TRISTE FIM DE POLICARPO QUARESMA
}

\author{
Michaella Araújo Farias* \\ Oriana Nadai Fulaneti**
}

\begin{abstract}
Resumo: Pretendemos neste trabalho trazer reflexões sobre a prática de ensino de leitura de textos literários a partir das diretrizes dos documentos oficiais acerca das capacidades de reconhecimento e interpretação dos mecanismos enunciativos, essencialmente as manifestações de vozes e pontos de vista, assim como os interlocutores e os papeis sociais. Nos balizaremos a obra Teoria do Romance de Mikhail Bakhtin (2015), na qual é abordada a estilística no romance. Enfocamos o Plurilinguismo, a estratificação de uma linguagem social, concretizada por meio de discursos e ações. Exemplificaremos o conceito na obra Triste Fim de Policarpo Quaresma, de Lima Barreto, concluiremos com algumas reflexões acerca da construção de planejamento didático que articule as concepções expostas e o ensino de leitura de textos literários.
\end{abstract}

Palavras-chave: Bakhtin. Plurilinguismo. Ensino de leitura de textos literários. Triste Fim de Policarpo Quaresma

\begin{abstract}
We aim to bring in this work reflections on the teaching reading practice of literary texts from the guidelines of the official documents concerning the recognition and interpretation capacities of enunciation mechanisms, essentially the manifestations of voices and points of view, as well as the interlocutors and the social roles. We will revolve around Mikhail Bakhtin's theory of the novel (2015), which is addressed to the stylistics in the novel. We focus on Plurilinguism, the stratification of a social language, concretized through discourses and actions. We will exemplify the concept in Lima Barreto's Sad End of Polycarpo Quaresma, and conclude with some reflections about the construction of didactic planning that articulates the exposed conceptions and the teaching of reading literary texts.
\end{abstract}

Keywords: Bakhtin.Plurilingualism.Teaching reading of literary texts.Sad End of Policarpo Quaresma.

\section{1-Algumas considerações prévias}

A década de 1970 é marcada pela mudança de perspectiva teóricometodológica na área da linguística. $\mathrm{O}$ texto passa a ser visto como principal objeto de estudo, no entanto, há análises linguísticas que passaram a considerar não somente a forma $^{1}$, mas a língua em uso. Este pensamento é resultante de várias correntes teóricas da linguística, entretanto, não nos deteremos aqui em fazer um recorte diacrônico, mas em refletir nos reflexos desta "virada" ou tendência pós-estruturalista no ensino brasileiro, essencialmente no de língua portuguesa. As Orientações Curriculares para o Ensino Médio (2006) confirmam e reiteram esta mudança ao afirmar que se fez necessária uma atualização pedagógica. $O$ texto passa a ser concebido como objeto multifacetado, sendo a multiplicidade constituinte de uma totalidade. Para melhor compreensão, a OCEM traz as dimensões que o constroem e devem ser apreendidas pelo estudante.

\footnotetext{
*Mestranda pelo Programa de Pós-Graduação em Linguística da Universidade Federal da Paraíba. araujomichaella@gmail.com

** Professora na graduação em Letras (virtual e presencial) . Docente no Programa de Pós-graduação em Linguística da Universidade Federal da Paraíba. oriful@ hotmail.com

${ }^{1}$ Para entender mais sobre este contexto histórico e epistemológico recomendamos a leitura do ensaio Evolução dos Estudos Linguísticos. Disponível em: http://www.ufjf.br/praticasdelinguagem/files/2014/09/160-198Evolu\%C3\%A7\%C3\%A3o-dos-estudos-lingu\%C3\%ADsticos.pdf . Acesso em 04 de janeiro de 2018.
} 
(a) linguística, vinculada, portanto, aos recursos linguísticos em uso (fonológicos, morfológicos, sintáticos e lexicais);

(b) textual, ligada, assim, à configuração do texto, em gêneros discursivos ou em sequências textuais (narrativa, argumentativa, descritiva, injuntiva, dialogal);

(c) sociopragmática e discursiva, relacionada, por conseguinte: - aos interlocutores; - a seus papéis sociais (por exemplo, pai/filho, professor/aluno, médico/ paciente, namorado/namorada, irmãos, amigos, etc., que envolvem relações assimétricas e/ou simétricas); • às suas motivações e a seus propósitos na interação (como produtores e/ou receptores do texto); • às restrições da situação (instituição em que ocorre, âmbito da interação (privado ou público), modalidade usada (escrita ou falada), tecnologia implicada, etc.); - ao momento social e histórico em que se encontram engajados não só os interlocutores como também outros sujeitos, grupos ou comunidades que eventualmente estejam afeitos à situação em que emerge o texto.

(d) cognitivo-conceitual, associada aos conhecimentos sobre o mundo -objetos, seres, fatos, fenômenos, acontecimentos, etc. - que envolvem os conceitos e suas inter-relações. (OCEM 2016, p.22)

Percebemos que tal documento converge com o conceito de dialogismo, segundo o qual o texto não é imanente e tem um fim em si. Os textos basilares da educação no Brasil se amparam em parte na perspectiva dialógica, desenvolvida por Bakhtin e seu círculo.

Segundo Fiorin, o conceito de dialogismo em Bakhtin não está atrelado à ideia de um diálogo face a face entre interlocutores, mas sim entre discursos, já que "o interlocutor só existe enquanto discurso" (FIORIN, 2006, p. 166 apud Marcuzzo 2008 p. 5). Fiorin acrescenta também que por isso "todo enunciado possui uma dimensão dupla, pois revela duas posições: a sua e a do outro" (ibid., p. 5). Nesta perspectiva, o ensino de língua portuguesa deve compreender práticas pedagógicas voltadas às práticas sociais, à linguagem enquanto instância/espaço de interação. Contemplando esta abordagem as OCEM recomendam que o estudante seja orientado em seu trabalho de análise a

[...] a compreender o funcionamento sociopragmático do texto - seu contexto de emergência, produção, circulação e recepção; as esferas de atividade humana (ou seja, os domínios de produção discursiva); as manifestações de vozes e pontos de vista; a emergência e a atuação dos seres da enunciação no arranjo da teia discursiva do texto; a configuração formal (macro e microestrutural); os arranjos possíveis para materializar o que se quer dizer; os processos e as estratégias de produção de sentido. O que se prevê, portanto, é que o aluno tome a língua escrita e oral, bem como outros sistemas semióticos, como objeto de ensino/estudo/aprendizagem, numa abordagem que envolva ora ações metalinguísticas (de descrição e reflexão sistemática sobre aspectos linguísticos), ora ações epilinguísticas (de reflexão sobre o uso de um dado recurso linguístico, no processo mesmo de enunciação e no interior da prática em que ele se dá), conforme o propósito e a 
natureza da investigação empreendida pelo aluno e dos saberes a serem construídos. (OCEM 2016, p.32-33)

A seção denominada "Conhecimentos de literatura " retoma a estruturação dos textos e a distribuição de vozes, a multiplicidade de sentidos produzidos, além de vislumbrar o princípio dialógico. Elucidando que:

Embora não tenha explicitamente tratado da recepção ou dos efeitos da obra de arte sobre o leitor, Bakhtin, ao desenvolver o conceito de polifonia, chamando a atenção para a dimensão dialógica do texto, apontou para sua pluralidade discursiva, que ultrapassa os limites da estrutura interna da obra, estendendo-se à leitura. A palavra plural, disseminadora de sentidos, requer uma leitura também ela múltipla, não mais regulada pela busca do significado único ou pela verdade interpretativa, mas atenta às relações e às diferentes vozes que se cruzam nos textos literários. (OCEM 2006,p. 65 -66)

Apesar de defender o ensino interdisciplinar, os documentos oficiais não expõem claramente uma articulação entre o ensino de língua e literatura.No entanto, é sabido que é por meio da linguagem e seus mecanismos que os textos literários são produzidos, além de serem acervos históricos, sociais e expressivos da humanidade. Alguns cursos de Licenciatura em Letras Português já compreendem esta importância e trabalham em conjunto projetos de estágio supervisionado que imbricam as duas disciplinas. Uma experiência positiva pode ser observada na Universidade Federal da Paraíba. ${ }^{2}$ Alguns referenciais curriculares do Brasil recomendam esta prática nas salas de aula da educação básica, a exemplo do Rio Grande do Sul, como pode ser lido na citação abaixo.

Estudar língua e literatura em uma única disciplina decorre do entendimento de que, em ambas, o centro está no texto e ambas são fenômenos eminentemente dialógicos, frutos do trabalho de linguagem de sujeitos históricos, da ação interacional de sujeitos situados. A união desses componentes numa única disciplina fundamenta-se, ainda, na intensa relação que se estabelece entre os fenômenos da língua e da literatura na constituição histórica do português como língua representativa de uma cultura. Além disso, não apenas a linguagem é a matéria-prima a partir da qual a literatura é constituída, mas a literatura é, entre os diferentes usos da língua portuguesa, aquele mais vinculado à produção de um conhecimento de si e do mundo especificamente fundado no fenômeno da língua, limitado ao mesmo tempo por seus constrangimentos e viabilizado pelos seus potenciais expressivos. Aprender e ensinar língua portuguesa significa também aprender e ensinar literatura, e vice-versa (grifos das autoras, RIO GRANDE DO SUL, 2009, p. 53 apud Segabinazi e Lucena 2016 p.8).

Concordantes com esta perspectiva partiremos do conceito de Plurilinguismo, retomaremos a experiência das professoras de estágio supervisionado da Universidade

\footnotetext{
${ }^{2}$ Para um maior aprofundamento nesta experiência recomendamos a leitura do artigo: Aulas de língua portuguesa e literatura: concepções e orientações para uma metodologia de ensino integradora. Disponível em: http://www.ufpb.br/geef/contents/documentos/12-42-2-pb.pdf
} 
Federal da Paraíba, para enfim tecermos algumas reflexões e considerações sobre o ensino de língua e literatura retomando Rosas (2016).

Elegemos a obra Teoria do Romance de Mikhail Bakhtin (2015), na qual é abordada a estilística no romance. Entendemos que a obra acima citada apresenta muitas contribuições para um ensino que conecte língua e literatura, contemplando tanto aspectos estilísticos/ linguísticos. Elegemos para esta proposição a obra Triste Fim de Policarpo Quaresma. A escolha da obra foi motivada pela riqueza em papeis sociais explorados por meio dos personagens, a exemplo do Major (Policarpo Quaresma), Coronel Albernaz (vizinho de Policarpo), Tia Maria (lavadeira da família de Quaresma), Olga (afilhada de Policarpo), entre outros personagens que são , para os documentos oficiais, manifestação da dimensão sócio-pragmática e discursiva da linguagem e, para Bakhitin, materialização da estratificação da linguagem, da presença do Plurilinguismo ${ }^{3}$ ( heterodiscurso) no romance. ${ }^{4}$ Os estudos bakhtinianos têm por corpus majoritariamente prosas romanescas. Os romances têm por característica ser uma espécie de redoma dos conflitos humanos, ideologias, vozes sociais dentre outras amostras da vida em sociedade, do discurso cotidiano. Segundo Bakhtin (2015) a orientação dialógica do discurso entre discursos alheios (de todos os graus e qualidades do alheio) cria possibilidades novas e essenciais do discurso literário, seu peculiar potencial de prosa literária, que encontrou sua expressão mais plena e mais profunda no romance. Nesta perspectiva entendemos a necessidade e as possibilidades da realização de um letramento literário que considere os mecanismos linguísticos não apenas como organizadores textuais, mas produtores de sentido. Fonseca também defende esta visão de indissociabilidade ao discorrer que:

"Língua" e "literatura" são termos que se associam de um modo quase
automático, formando um sintagma sólido e coeso. Nomeadamente
quando se fala de ensino. [...]Não se trata de ensinar língua mais
literatura ou de ensinar língua e depois literatura, mas de ter
consciência de que faz parte da competência do falante e está nela
fundamente enraizada desde as fases mais precoces da aprendizagem
linguística a capacidade de explorar as amplas virtualidades cognitivas
e lúdico catárticas de uma relação autotélica com a língua
(FONSECA,2016,p.1)

Importante salientar que é preciso ter cautela ao utilizar o texto literário no ensino de língua, tendo em vista que é sabida e muito discutida a prática da apropriação do texto literário ou de fragmentos, não apenas do texto literário como de demais esferas, para ensinar normas gramaticais, atitude que é chamada pela academia e por alguns estudiosos de " texto como pretexto". Exporemos alguns exemplos de Plurilinguismo na obra escolhida e de como este fenômeno se configura linguisticamente. Pretendemos também expor algumas reflexões, para que professores e/ou estudantes possam elaborar atividades didáticas-pedagógicas que abarquem esta concepção bakhtiniana e articulem linguagem e literatura.

\footnotetext{
3 O uso das nomenclaturas varia de Plurilinguismo para Heterodiscurso de acordo com a tradução. Heterodiscurso em BAKHTIN, M. BAKHTIN, M. Teoria do romance I: a estilística. Tradução: Paulo Bezerra. São Paulo: Editora 34, 2015 e Plurilinguismo em : BAKHTIN, M. Questões de literatura e de estética: a teoria do romance. Trad. Aurora Fornoni Bernardini et al. $3^{\text {a }}$ ed. São Paulo: Unesp; Hucitec, 1993[1934-1935].
} 


\section{2- Plurilinguismo em Triste Fim de Policarpo Quaresma}

O homem para Bakhtin não é um ser meramente biológico, mas um ser histórico-social, sendo assim, é revestido por valores, intenções, desejos, ações, entre outros, não é diferente no romance, e é por meio da linguagem que estas características humanas se manifestam no discurso romanesco. O homem no romance é dotado de discurso e este discurso por sua vez se materializa no texto, organizado e disposto por escolhas estilísticas da autoria, que também é um sujeito. Estes sujeitos estão em um mundo real ou virtual e são afetados por contextos histórico-sociais.

Segundo Bakhtin (2015) no romance devem ser consideradas as várias linguagens existentes, as quais ele nomeia plurilinguismo. Tomemos, para efeito de ilustração, a linguagem do médico, do camponês, do homem urbano, da religião, a esta estratificação Bakhtin nomeará plurilinguismo social. A pluridiscursividade se realiza intra e extraliterariamente, no entanto, deve ser considerada como constituinte e orientadora da estilística do romance. Sobre a materialização discursiva do plurilinguismo no romance faz-se pertinente afirmar conforme Bakhtin:

O plurilinguismo, desta forma, penetra no romance, por assim dizer, em pessoa e se materializa nele nas figuras que falam, ou então servindo como fundo um diálogo, determina a ressonância espacial do discurso direto do romance. Disto se segue uma característica extraordinariamente importante do gênero romanesco: o homem no romance é essencialmente o homem que fala; o homem necessita de falantes que the tragam seu discurso original, sua linguagem. (BAKHTIN 1993, p.134)

Como dito antes, tomaremos a obra de Lima Barreto intitulada Triste Fim de Policarpo Quaresma. No romance temos várias evidências do plurilinguismo na fala dos personagens, dos quais elegemos dois, a tia Maria Rita, uma antiga lavadeira da casa dos Albernaz, e o próprio Policarpo Quaresma, o major.

O trecho escolhido relata a ida do Major Quaresma e do Coronel Albernaz à casa da antiga criada de sua família para buscar antigas cantigas para serem acompanhadas pelo violão de Quaresma.

O personagem protagonista (da obra eleita como corpus) busca por uma identificação, uma cultura genuinamente nacional (brasileira), este intuito move a ação do personagem a ir procurar " Tia Maria“ a fim de aprender as músicas para uma festa que seria dada pelo Coronel Albernaz. O narrador cede a voz às personagens e encontraremos o seguinte diálogo:

O general, que a velha chamava coronel, por tê-lo conhecido nesse posto, não atendeu a observação da moça e insistiu:

- Qual esquecida, o quê! Deve saber ainda alguma cousa, não é, titia?

- Só sei o "Bicho Tutu", disse a velha.

- Cante lá!

- Ioiô sabe! Não sabe? Quá, sabe!

- Não sei, cante. Se eu soubesse não vinha aqui.

Pergunte aqui ao meu amigo, o Major Policarpo, se sei.

Quaresma fez com a cabeça sinal afirmativo e a preta velha, talvez com grandes saudades do tempo em que era escrava e ama de alguma grande casa, farta e rica, ergueu a cabeça, como para melhor recordarse, e entoou: 
É vem tutu

Por detrás do murundu

Pra cumê sinhozinho

Cum bucado de angu.

(BARRETO 1995, p. 11-12)

Evidencia-se neste trecho, essencialmente na fala da "tia Maria", que a personagem faz parte de um estrato social mais baixo, evidenciado por exemplo no trecho " cumê", no qual ocorre o fenômeno de supressão do " $\mathrm{r}$ ", além da modificação das vogal média " o" por vogal alta "u" como ocorre em " cumê " e “bucado", o que é caracterizado por estudos ${ }^{5}$ de vertentes da sociolinguística como uma marca de falantes advindos do campo.

Bakhtin estabelece em Questões de Literatura e de Estética: a teoria do romance algumas categorizações para o homem que fala e sua palavra no romance, afirma que não se pode tratar o discurso do personagem como que se a qualquer outra coisa inanimada, acontecimento ou um fenômeno natural, mas toma-se o discurso como objeto para análise das representações sociais projetadas nas falas dos personagens. Aborda também a questão do discurso historicamente marcado, no qual a fala do personagem tem como objetivo marcar o lugar de onde ele fala, uma estratificação da linguagem. A construção da imagem da "velha preta " é reforçada pelo narrador ao afirmar " a preta velha, talvez com grandes saudades do tempo em que era escrava e ama de alguma grande casa, farta e rica" BARRETO,2005, p. 11) ao realizar a descrição da casa da tia Maria " A sala era pequena e de telha-vã. Pelas paredes, velhos cromos de folhinhas, registros de santos, recortes de ilustrações de jornais baralhavamse e subiam por elas acima até dous terços da altura." (s/d, p. 11). O dialeto da personagem em concordância com a descrição do narrador é de uma classe social menos favorecida e menos letrada do que a do coronel e a do major.

O homem no discurso romanesco não é apenas um ser que fala, mas também age, e suas ações são imersas em ideologia. Ainda segundo Bakhtin (2015), o sujeito é ideólogo, as palavras são ideologemas no discurso no romance e defendem sempre um ponto de vista e suas ações são investidas desta ideologia, o que podemos constatar no personagem Quaresma. Desenganado com a tentativa fracassada de encontrar música nacional indo ao encontro da "Tia Maria Rita ", soube notícias de um velho poeta que poderia ajudá-lo, o velho contou-lhe a história do " Tangolomango" e após leituras e estudos o Major Quaresma descobriu que a história fora importada. Após esta desilusão pôs-se a buscar algo próprio de sua nação, debruçou-se sobre os estudos novamente, tendo passado semanas lendo sobre os costumes dos tupinambás. Dez dias depois foi interrompido em seus estudos e reagiu da seguinte forma:

\footnotetext{
Abriu, mas não apertou a mão. Desandou a chorar, a berrar, a arrancar os cabelos, como se tivesse perdido a mulher ou um filho. A irmã correu lá de dentro, o Anastácio também, e o compadre e a filha, pois eram eles, ficaram estupefatos no limiar da porta.

- Mas que é isso, compadre?

- Que é isso, Policarpo?

- Mas, meu padrinho...
}

\footnotetext{
${ }^{5}$ Para um maior aprofundamento sobre o fenômeno citado recomendamos a leitura do Trabalho de Conclusão de Curso de Menezes, Oliveira Cecília Maria. Variação Linguística: análise de uma comunidade de São Sebastião -DF. UNB - 2007, disponível em : http://sociolingustica.blogspot.com/2007/10/variao-lingstica-anlise-de-uma.html Acesso em ; 10 de maio de 2018.
} 
Ele ainda chorou um pouco. Enxugou as lágrimas e, depois, explicou com a maior naturalidade:

- Eis aí! Vocês não têm a mínima noção das cousas da nossa terra. Queriam que eu apertasse a mão. Isto não é nosso! Nosso cumprimento é chorar quando encontramos os amigos, era assim que faziam os tupinambás. (BARRETO, 1995, p.14)

Como dito antes, Quaresma buscava uma cultura genuinamente brasileira, seus discursos e suas ações são sublinhadas por sua ideologia, que são divergentes da dos outros personagens, mas convergentes com as concepções de mundo do personagem.

Oliveira (2002) ao discorrer sobre as contribuições do círculo bakhitiniano para o ensino da língua portuguesa evidencia que a partir da visão do texto a partir das relações entre enunciado e realidade e seu produtor e os interlocutores, pressupõe mudanças sobre as quais ela discorre;

Operar metodologicamente e didaticamente com estes dois tipos de relações, implica assumir outras categorias de análise incorporando ao ensino e aprendizagem da língua materna, questões relacionadas ao sujeito do discurso, passando, portanto, pela noção de valor, das vozes sociais de suas relações dialógicas. (OLIVEIRA, 2002, p. 3)

A obra de Lima Barreto é um exemplo de como obras literárias oportunizam abordagem de elementos de estilo e todos os recursos linguísticos utilizados. Além do Plurilinguismo, assim como a fala e o estilo de cada personagem, aspectos que renderia um grande trabalho. No entanto o que se pretendeu aqui foi ilustrar a presença do Plurilinguismo na obra Triste Fim de Policarpo Quaresma, e a partir disto, refletir sobre o ensino de leitura de texto literário. Dispomos de um quantitativo farto de obras que poderiam ser abordadas nesta perspectiva, é fato que é um desafio, mas é inegável que é a necessidade de (re) pensar no ensino de literatura é irrefutável.

\section{3- Proposta(s) de reflexão(ões) para elaboração de um planejamento didático}

A articulação entre o ensino de literatura e linguagem deve ser cuidadosamente planejado e pensado, para que como já comentado, não se atenha à identificação de normas gramaticais ou de prescrições de leitura e escrita. Retomando as concepções elencadas pelos referenciais de ensino, concordamos aqui que o fazer docente precisa considerar as múltiplas dimensões do texto, assim como considerar a estrutura composicional, as marcas linguísticas, os mecanismos discursivos e os efeitos de sentido produzidos.

Apesar de os documentos oficiais não abordarem um trabalho que articule língua e literatura, assim como os livros didáticos, em sua maioria, também não o fazem. Várias propostas de organização de sequências didáticas vêm sendo desenvolvidas, com destaque para os estudos do interacionismo sociodiscursivo, perspectiva adotada pelos referenciais nacionais. Nesta conjuntura, indicamos $o$ caminho recomendado pela professora Maria do Socorro Rosas. 
Figura 1: Etapas para sequência didática de ensino de gêneros literários

\begin{tabular}{|c|c|}
\hline DO POKTO DE VISTA DO PROFISSOR & DO POWTO DE VISTA DO ALUKO \\
\hline $\begin{array}{l}\text { 1. Selecionar um gênero textual, em função das habilidades que } \\
\text { se quer desenvolver. }\end{array}$ & \multirow{3}{*}{$\begin{array}{l}\text { 1. Compreender o porquê de estudar o gênero } \\
\text { selecionado pelo professor. }\end{array}$} \\
\hline $\begin{array}{l}\text { 2. Definir as condiçōes de circulação social desse gênero, para } \\
\text { planejar um conjunto de atividades que possibilitem transpor, } \\
\text { para a situação de ensino do gênero, essas condições } \\
\text { ("imitando-as" ou "ficcionalizando-as"). }\end{array}$ & \\
\hline $\begin{array}{l}\text { 3. Planejar as atividades e ordená-las numa sequência que } \\
\text { possibilite aos alunos compreender os passos ou etapas da } \\
\text { produção do texto. }\end{array}$ & \\
\hline 4. Explicitar aos alunos os objetivos de cada etapa & $\begin{array}{l}\text { 2. Compreender os objetivos de cada atividade da } \\
\text { sequência, a fim de entender o porquê de sua } \\
\text { realização. }\end{array}$ \\
\hline 5. Negociar com os alunos a realização das atividades & $\begin{array}{l}\text { 3. Realizar as atividades de acordo com as } \\
\text { instruçöes do professor. }\end{array}$ \\
\hline 6. Avaliar os resultados atingidos, explicitando-os aos alunos. & $\begin{array}{l}\text { 4. Participar da avaliação dos resultados das } \\
\text { atividades realizadas. }\end{array}$ \\
\hline
\end{tabular}

Fonte: Rosas (2006)

Como podemos observar a leitura é posta de uma forma esquematizada, sistemática e o estabelecimento de objetivos é pertinente ao processo de avaliação de resultados alcançados. Rosas (2006) sugere que por meio da sequência didática seja possível estabelecer um projeto de vivências literárias que englobem os conteúdos já contemplados pela escola a exemplo dos estudos linguísticos, leitura e escrita. O nosso principal questionamento aqui é se estes conteúdos ditos " predominantes " estão ou não sendo seccionados em diversas disciplinas, tais como produção de textos, língua e literatura.

Em nossa pesquisa não encontramos exemplos de propostas didáticas que contemplassem o Plurilinguismo/heterodiscurso e o ensino de literatura. A partir da leitura da obra acreditamos que há possibilidade de trabalhar o conceito ilustrado neste trabalho, e para além deste conceito, é possível também expandir a proposta para outros conteúdos programáticos ou imbrica-los. Por exemplo, podem ser trabalhados os tipos de discurso - direto, indireto, indireto livre e como o narrador se aproxima e se distancia do enunciado e qual efeito de sentido este movimento produz. Tal estratégia composicional também é uma ferramenta de construção dos enunciados, a qual Bakhtin trabalha brilhantemente em Teoria do Romance.

Um maior aprofundamento na obra de Bakhtin e uma leitura na íntegra do romance seriam capazes de exemplificar e identificar outras questões estilísticas composicionais do romance abordado. No entanto, no momento, o objetivo foi expor sumariamente manifestações do Plurilinguismo, e das construções do discurso do homem que fala no romance, o qual se faz por personagens, que por sua vez são revestidos por dialetos próprios, estratificados de uma linguagem social, e investidos por ideologias que se concretizam por meio de discursos e ações.

\section{4- Considerações Finais}

O ensino de Língua Portuguesa no Ensino Médio em nosso país, de acordo com os documentos oficiais, passa, hoje, por um processo de transformação de concepções e de revisão do objeto de ensino da língua para os Referencias Curriculares do Ensino Médio. Os moldes tradicionalistas do ensino de língua, fundamentados no aprendizado da nomenclatura e do estudo dos aspectos fonológicos, morfológicos e 
sintáticos afastados do uso e das aplicações práticas, são a causa do abismo que há entre o aluno de Ensino Médio e o domínio pleno de sua língua materna. Em decorrência disto, os Parâmetros Curriculares Nacionais (2000), assim como as Orientações Currículares - OCEM (2006) e os Referenciais Curriculares - RCEM vêm propondo uma reavaliação das concepções de ensino de língua portuguesa no ensino médio, objetivando unir o processo metodológico e teórico do ensino com as aplicações práticas e os diversos posicionamentos da linguagem dentro da sociedade.

Vimos no decorrer deste artigo que o gênero romance se configura como um reduto de manifestação de ideologias, práticas sociais e de diversos gêneros discursivos em sua composição. Não defendemos aqui um retorno ao ensino do conteúdo em detrimento da forma, mas a conjunção entre expressão e conteúdo. Acreditamos que a literatura forma leitores mais críticos, humanizados e conscientes dos seus papeis enquanto sujeitos, pois só há transformação social, quando há consciência da realidade social em que se se vive. Os postulados bakhtinianos colocam o sujeito no centro dos estudos linguísticos e as interações deste sujeito com o outro e com o mundo, no centro das relações sociais. O autor ainda coloca a palavra como arena de combate, de confronto de ideologias.

A partir das reflexões realizadas na escrita deste trabalho pudemos considerar que a identificação das vozes facilita o encontro da sua própria, do seu posicionamento enquanto sujeito, no concordar ou discordar. A realização deste estudo se propôs não a solucionar o problema da separação do ensino de língua ou de literatura, mas a levantar questões sobre esta problemática e de propor a partir disto ,possibilidades que dialoguem com os documentos referenciais e a concepção de dialogismo e polifonia bakhtinianas.

Esperamos colaborar com professores em exercício e em formação que tenham interesse numa prática de ensino de leitura de textos literários e não-literários (nomenclatura questionável), que considerem a percepção dos mecanismos disponíveis na língua e utilizados pelos usuários na produção e recepção de sentido.

\section{Referências}

BAKHTIN, M. Teoria do romance I: a estilística. Tradução: Paulo Bezerra. São Paulo: Editora 34, 2015.

BAKHTIN, M. Questões de literatura e de estética: a teoria do romance. Trad. Aurora Fornoni Bernardini et al. $3^{a}$ ed. São Paulo: Unesp; Hucitec, 1993[1934-1935], p.

BARRetO, Lima. Triste fim de Policarpo Quaresma. 17. ed. São Paulo: Ática, [s.d.]. (Bom Livro). Texto proveniente de: A Biblioteca Virtual do Estudante Brasileiro A Escola do Futuro da Universidade de São Paulo Permitido o uso apenas para fins educacionais.

BRASIL, Linguagens, códigos e suas tecnologias, Orientações curriculares para o ensino médio; volume 1/ Secretaria de Educação Básica. - Brasília: Ministério da Educação, Secretaria de Educação Básica, 2006.

FONSECA, F. I. Da inseparabilidade entre o ensino da língua e do ensino da literatura. Disponível em:https://repositorio- 
aberto.up.pt/bitstream/.../irenefonsecainsaperabilidade000083607.p... Acesso em: 07 de janeiro de 2018

MARCUZZO, Patrícia. Diálogo inconcluso: os conceitos de dialogismo e polifonia na obra de Mikhail Bakhtin. Cadernos do IL, Porto Alegre, n. ${ }^{\circ}$ 36, junho de 2008. Disponível em: http://www.seer.ufrgs.br/cadernosdoil/. Acesso em 03 de janeiro de 2018.

OLIVEIRA, F. de Maria Bernadete. Contribuições do círculo bakhtinianos ao ensino de língua materna. Periódicos UFRN - GELNE - V. 4, n. 1. Disponível em: https://periodicos.ufrn.br/gelne/article/view/9135 Acesso em : 21 de janeiro de 18

PARAÍBA, Secretaria de Educação e Cultura. Referenciais Curriculares: Língua Portuguesa. João Pessoa, 2004

SEGABINAZI, Daniela Maria e LUCENA, de Marinho Josete. Aulas de língua portuguesa e literatura: concepções e orientações para uma metodologia de ensino integradora. Linguagens \& Letramentos, v.1, $\mathrm{n}^{\circ} 1$ (2016). Disponível em: http://www.ufpb.br/geef/contents/documentos/12-42-2-pb.pdf Acesso em 06 de janeiro de 2018. 